\title{
Pharmacokinetics of enantiomers of oxiracetam in rats
}

\author{
Wu-San Wang ${ }^{1 *}$, Yu-Feng Wen ${ }^{2}$ \\ ${ }^{1}$ Department of Pharmacology, College of Pharmacy, ${ }^{2}$ School of Laboratory Medicine, Wannan Medical College, Wuhu, Anhui \\ Province 241002, China
}

*For correspondence: Email: vq1277@163.com

Sent for review: 13 June 2018

Revised accepted: 27 November 2018

\begin{abstract}
Purpose: To investigate the differences in pharmacokinetics of S-oxiracetam (S-ORT) and $R$ oxiracetam $(R-O R T)$ in rats.

Methods: Sprague-Dawley rats (20) were randomly divided into two groups (ten rats per group), viz, SORT and R-ORT groups. Rats in S-ORT group received $200 \mathrm{mg} \mathrm{S}$-ORT/kg while rats in R-ORT group were given $200 \mathrm{mg} R-O R T / \mathrm{kg}$. Both treatments were given orally, and blood samples were collected at fixed time intervals for analysis. Ultra performance liquid chromatography-electrospray ionizationtandem mass spectrometry (UPLC-ESI-MS/MS) was used for pharmacokinetic analysis. Portions of the rat plasma were also subjected to configurational transformation analysis using normal phase-high performance liquid chromatographic (NP-HPLC) fitted with a Chiral OC column. Blank blood samples from five rats were used for plasma protein binding rate studying.

Results: The two enantiomers did not transform into each other after oral administration, and the concentrations of S-ORT at 1, 1.5 and $2 \mathrm{~h}$ were significantly higher than those of R-ORT $(p<0.05)$. The area under the curve $\left(A \cup C_{0-\infty}\right)$ and maximum concentration $\left(C_{\max }\right)$ of S-ORT were also significantly larger than those of R-ORT $(p<0.05)$. There were no stereoselective differences between the two enantiomers.

Conclusion: There are significant differences in absorption between two ORT enantiomers, and this may result in different pharmacological effects.
\end{abstract}

Keywords: S-oxiracetam, R-oxiracetam, Configuration, Pharmacokinetics, Rats

\begin{abstract}
This is an Open Access article that uses a funding model which does not charge readers or their institutions for access and distributed under the terms of the Creative Commons Attribution License (http://creativecommons.org/licenses/by/4.0) and the Budapest Open Access Initiative (http://www.budapestopenaccessinitiative.org/read), which permit unrestricted use, distribution, and reproduction in any medium, provided the original work is properly credited.
\end{abstract}

Tropical Journal of Pharmaceutical Research is indexed by Science Citation Index (SciSearch), Scopus, International Pharmaceutical Abstract, Chemical Abstracts, Embase, Index Copernicus, EBSCO, African Index Medicus, JournalSeek, Journal Citation Reports/Science Edition, Directory of Open Access Journals (DOAJ), African Journal Online, Bioline International, Open-J-Gate and Pharmacy Abstracts

\section{INTRODUCTION}

Chiral compounds constitute more than $50 \%$ of pharmaceuticals in use currently, and biomolecules such as proteins, amino acids, fatty acids, nucleic acids, and monosaccharides exhibit chirality. Enantiomers have the same physicochemical properties, but may exhibit differences in pharmacokinetics, pharmacodynamics, and toxicity [1].
Oxiracetam (ORT) belongs to the cyclic $\mathrm{Y}^{-}$ aminobutyric acid class of drugs and as a nootropic agent, it is used to treat various cognitive disorders due to its ability to promote both learning and memory processes [2-5]. In clinical practice, it is used as a racemic mixture of S-ORT) and R-ORT (Figure 1). 

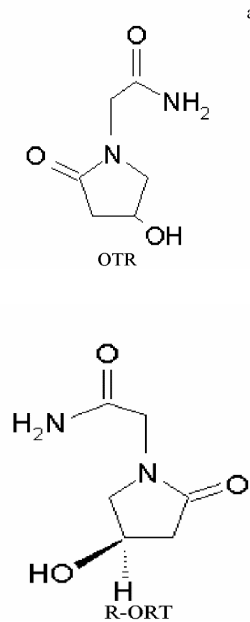

Figure 1: Chemical structures of ORT and its enantiomers

The $S$ enantiomer of ORT is more biologically active than the $\mathrm{R}$ form, probably due to differences in their pharmacokinetics [6,7]. The aim of the present study was to investigate the differences in pharmacokinetics of S-ORT and RORT in rats.

\section{EXPERIMENTAL}

\section{Chemicals and reagents}

All chemicals and solvents used in this study were of analytical grade. The enantiomers of ORT were products of Nanjing Yoko Biomedical Research Co. Ltd., while piracetam (internal standard) was obtained from the National Institute for Food and Drug Control, Beijing, China. High-performance liquid chromatography (HPLC) grade n-hexane was bought from Tedia (USA).

\section{Experimental rats}

A total of 25 rats of Sprague-Dawley strain were used in this study. They were purchased from the Shanghai Institute of Xingang Experimental Animal Center, and housed in iron cages with free access to food and water. Twenty of the rats were randomly divided into two equal groups of ten rats each: S-ORT and R-ORT, while the remaining five rats were used to obtain blood samples which served as blank in the analysis of plasma protein binding. Rats in S-ORT group received $200 \mathrm{mg} \mathrm{S}-\mathrm{ORT} / \mathrm{kg}$, while rats in R-ORT group were given $200 \mathrm{mg} \mathrm{R}-\mathrm{ORT} / \mathrm{kg}$ BW. Both treatments were administered orally.

After drug administration, $0.2 \mathrm{~mL}$ of blood sample was collected from the orbital venous plexus of each rat at $0,0.08,0.25,0.5,0.75,1,1.5,2,4,6$, 8,12 , and $24 \mathrm{~h}$ in anti-coagulated tubes. The blood samples were centrifuged at $4000 \mathrm{rpm}$ for $5 \mathrm{~min}$ and the plasma obtained stored at $-80{ }^{\circ} \mathrm{C}$ until analysis. Plasma samples at different time interval were used for pharmacokinetic studies, while portions of the plasma at $0,1,1.5$, and $2 \mathrm{~h}$ were used for configurational transformation analysis. Ethical clearance for the animal experiments was obtained from the Ethics Committee of the Yijishan Hospital (approval no. 20170116) and international guidelines for animal studies were followed [8].

\section{Chromatographic conditions}

\section{Enantiomer transformation}

Enantiomers of ORT were separated using a Waters HPLC system equipped with a binary pump, a thermostated column oven and a UV detector. Chromatographic separation was carried out on a Chiral OC Daicel $(4.6 \times 250 \mathrm{~mm})$ column. The column temperature and detection wavelenght were set at $30{ }^{\circ} \mathrm{C}$ and $210 \mathrm{~nm}$, resprctively, while the injected volume was 50 $\mu \mathrm{L}$. The isocratic mobile phase which consist of a mixture of hexane and ethanol $(75: 25, \mathrm{v} / \mathrm{v})$, was delivered at $1.0 \mathrm{ml} / \mathrm{min}$ and the run time for each sample was $18 \mathrm{~min}$.

\section{Pharmacokinetics and plasma protein binding rate studies}

Sensitive UPLC-ESI-MS/MS was used to measure plasma S-ORT and R-ORT concentrations. A Shimadzu LC system equipped with a binary pump, vacuum degasser, and a thermostated column oven. Temperatures of the column and autosampler were maintained at 40 and $4{ }^{\circ} \mathrm{C}$, respectively, and the chromatographic separation was performed on an HP amide LCMS/MS column ( $100 \mathrm{~mm} \times 3.00 \mathrm{~mm}, 5 \mu \mathrm{m})$. The isocratic mobile phase which consisted of a mixture of methanol and water $(85: 15, \mathrm{v} / \mathrm{v})$, was delivered at $0.2 \mathrm{ml} / \mathrm{min}$ and the run time for each sample was $5 \mathrm{~min}$. Positive ion mode fitted with multiple reaction monitors was used for detection (mass transition $(\mathrm{m} / \mathrm{z}) 159.0 \rightarrow 114.1$ and 143.0 $\rightarrow 126.1$ for ORT and piracetam, respectively).

\section{Samples and standards}

A portion of the plasma $(200 \mu \mathrm{L})$ and $40 \mu \mathrm{L}$ acetonitrile-water solution $(50: 50, \mathrm{v} / \mathrm{v})$ were added to an Eppendorf tube spiked with $20 \mu \mathrm{L}$ of piracetam, (internal working standard solution), and vortexed for $2 \mathrm{~min}$. This was followed by the addition of $0.6 \mathrm{~mL}$ of acetonitrile, and vortexing again for another $2 \mathrm{~min}$. The resultant mixture was centrifuged at $12,000 \mathrm{rpm}$ at $4{ }^{\circ} \mathrm{C}$ for $5 \mathrm{~min}$, and $2 \mathrm{~mL}$ of the supernatant was collected, and 
dried with liquid nitrogen in a thermostated water bath at $38{ }^{\circ} \mathrm{C}$. After drying, $300 \mu \mathrm{L}$ of mobile phase solution was added, and the tube was again centrifuged at $12,000 \mathrm{rpm}$ at $4^{\circ} \mathrm{C}$ for 5 min. A portion of the resultant supernatant (100 $\mu \mathrm{L}$ ) was pipetted into an auto-sampler vial, out of which $50 \mu \mathrm{L}$ was injected into the column for analysis.

\section{Pharmacokinetic analysis}

Plasma sample spiked with piracetam was extracted with methanol and centrifuged at 12, $000 \mathrm{rpm}$ for $5 \mathrm{~min}$ at $4{ }^{\circ} \mathrm{C}$. The resultant supernatant was pipetted into an auto-sampler vial for analysis. Quality control (QC) samples of three different concentrations $(0.1,1$, and 40 $\mu \mathrm{g} / \mathrm{mL}$ ) in five replicates were used to assess the assay performance. Both enantiomers analyses were performed within a concentration range of 0.05 - $50 \mu \mathrm{g} / \mathrm{mL}$. Inter-assay precision and accuracy were determined by comparing with values obtained for the QC samples.

\section{Plasma protein binding studies}

A dialysis membrane bag was refluxed first with ethanol for $2 \mathrm{~h}$, and then with $0.01 \mathrm{M} \mathrm{NaHCO}_{3}$ solution for $30 \mathrm{~min}$, followed by multiple rinses with water to equilibrate it before the dialysis proper. Glass tubes (40 mL) were prepared for placement of the dialysis bag to create two chambers in it. Dialysates $(30 \mathrm{~mL})$ mixed with different concentrations of S-ORT $(0.5,2,10$ and $40 \mu \mathrm{g} / \mathrm{mL}$ ) and $1.0 \mathrm{~mL}$ of blank plasma was injected into the dialysis bag. The tubes were stoppered and the bag was tied and carefully immersed in Hank's balanced salt solution $(\mathrm{pH}$ 7.4).Dialysis took place while the bag was rotated at $10 \mathrm{rpm}$ at $37^{\circ} \mathrm{C}$ in a temperaturecontrolled water bath. After $24 \mathrm{~h}$ of dialysis, 50 $\mu \mathrm{L}$ of plasma and dialysate samples were withdrawn from the two chambers and stored at $20{ }^{\circ} \mathrm{C}$ until drug concentrations analysis. An aliquot $(50 \mu \mathrm{l})$ of the plasma or buffer dialysate, spiked with $10 \mu \mathrm{L}$ of piracetam was vortex-mixed for 30 secs and extracted with $1 \mathrm{~mL}$ of methanol using a vortex mixer for $1 \mathrm{~min}$. This was followed by centrifugation at $12,000 \mathrm{rpm}$ at $4{ }^{\circ} \mathrm{C}$ for $3 \mathrm{~min}$. A portion of the resultant supernatant $(100 \mu \mathrm{L})$ was pipetted into an auto-sampler vial, while 50 $\mu \mathrm{L}$ of it was injected into the column for analysis. The percentage drug-protein binding was calculated as in Eq 1.

Binding $(\%)=\left(1-\mathrm{C}_{\text {out }} / \mathrm{C}_{\text {in }}\right) \times 100$

where $\mathrm{C}_{\text {out }}$ is the concentration of drug outside the bag, and $C_{\text {in }}$ is the drug concentration inside the bag.

\section{Statistical analysis}

Data are expressed as mean \pm standard deviation (SD). Groups were compared using $t$ test and the statistical analysis was performed with Drug Supply Modelling Software (1.0). Values of $p<0.05$ were considered statistically significant.

\section{RESULTS}

\section{Stereo-chemical stabilities of enantiomers of ORT}

The retention times of R-ORT and S-ORT were 10.7 and $15.9 \mathrm{~min}$, respectively, and they did not transform into each other after oral administration to rats (Figure 2).
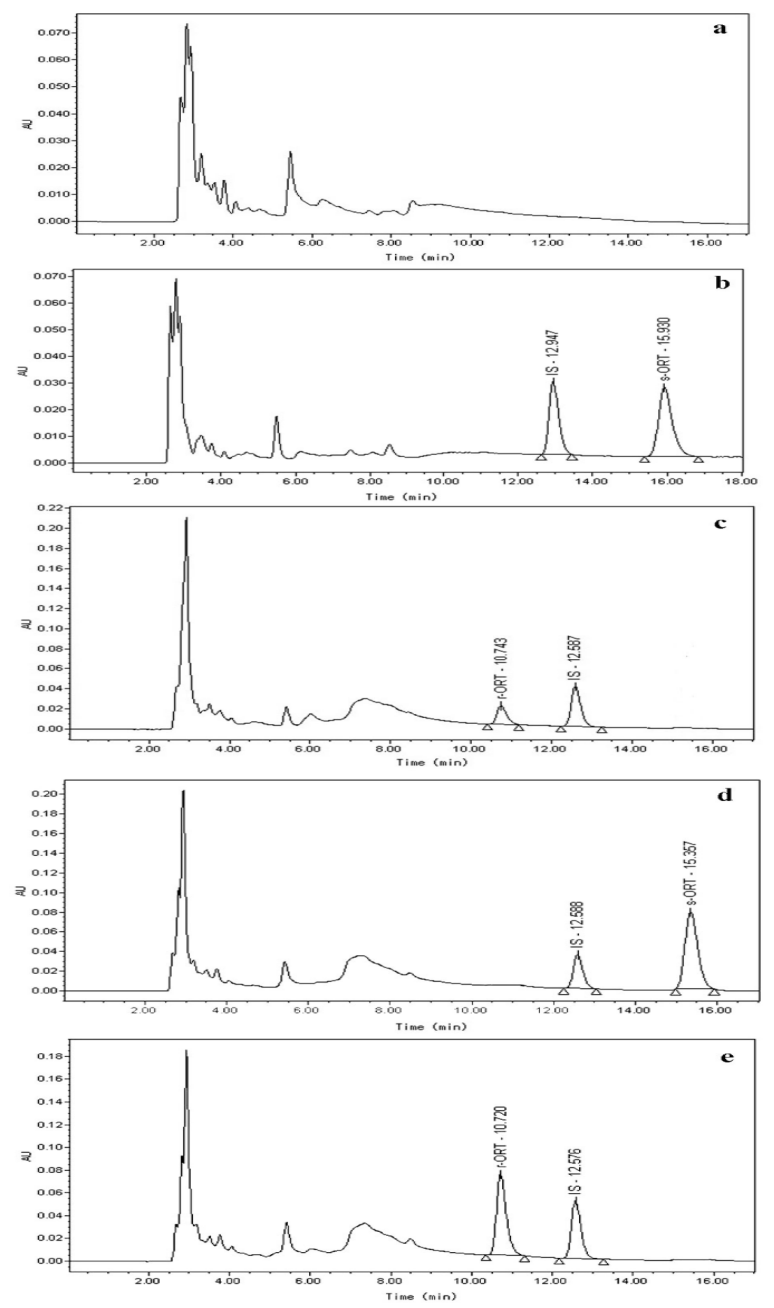

Figure 2: Normal phase-HPLC chromatograms of ORT samples. (a) blank rat plasma, (b) blank rat plasma spiked with $10 \mu \mathrm{g} / \mathrm{mL}$ of S-ORT, (c) blank rat plasma spiked with $10 \mu \mathrm{g} / \mathrm{mL}$ of R-ORT, (d) plasma sample $1.5 \mathrm{~h}$ after oral administration of $200 \mathrm{mg} \mathrm{S}$ ORT/kgand (e) plasma sample $1.5 \mathrm{~h}$ after oral administration of $200 \mathrm{mg} \mathrm{R}-\mathrm{ORT} / \mathrm{kg}$ 


\section{Pharmacokinetics of S-ORT and R-ORT in rats}

The time-concentration curves of S-ORT and RORT after oral administration to rats were best fitted as two-compartment open models, and the concentrations of S-ORT at $1,1.5$ and $2 \mathrm{~h}$ were higher $(p<0.05)$ than those of R-ORT at corresponding periods (Figure 3). The area under the curve $\left(A \cup C_{0-\infty}\right)$ and maximum concentration $\left(C_{\max }\right)$ of S-ORT after oral administration were also larger $(p<0.05)$ than those of R-ORT. The absorption half-life $\left(t_{1 / 2 \mathrm{ka}}\right)$, peak time $\left(t_{\max }\right)$, volume of distribution $\left(V_{\mathrm{d}}\right)$, elimination half-life $\left(t_{1 / 2 \beta}\right)$, systemic clearance $(C l)$, and mean resident time (MRT) of S-ORT were similar to those of R-ORT (Table 1).

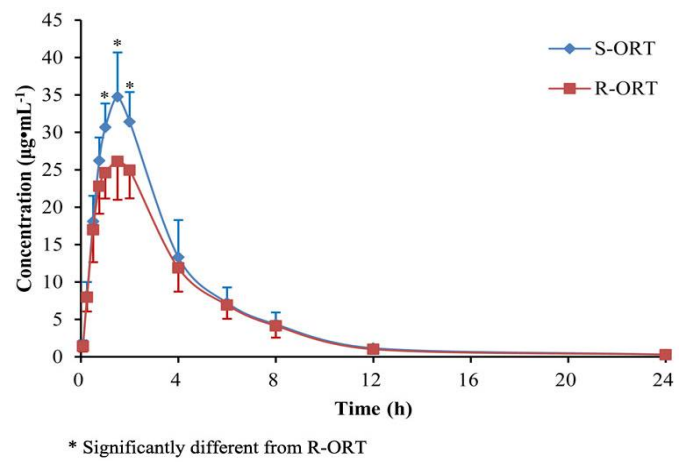

Figure 3: Mean plasma concentration vs time profiles after oral administration of S-ORT and R-ORT, each at $200 \mathrm{mg} / \mathrm{kg}$

Table 1: Pharmacokinetic parameters for S-ORT and R-ORT

\begin{tabular}{lcc}
\hline Parameter & S-ORT & R-ORT \\
\hline$t_{1 / 2 \alpha}(\mathrm{h})$ & $2.13 \pm 0.97$ & $1.99 \pm 0.71$ \\
$t_{1 / 2 \beta}(\mathrm{h})$ & $6.10 \pm 2.72$ & $6.06 \pm 3.13$ \\
$t_{1 / 2 \mathrm{ka}}(\mathrm{h})$ & $0.33 \pm 0.16$ & $0.31 \pm 0.25$ \\
$V_{d}(\mathrm{~L} / \mathrm{kg})$ & $8.79 \pm 3.77$ & $9.15 \pm 5.17$ \\
$C / / F(\mathrm{~L} / \mathrm{h} / \mathrm{kg})$ & $2.74 \pm 0.76$ & $3.03 \pm 0.73$ \\
$A U C_{0-\infty}(\mathrm{mg} / \mathrm{L} / \mathrm{h})$ & $153.13 \pm$ & $114.15 \pm 17.47$ \\
& $30.52^{\mathrm{b}}$ \\
$M R T_{0-\infty}(\mathrm{h})$ & $4.39 \pm 0.83$ & $4.67 \pm 0.72$ \\
$t_{\max }(\mathrm{h})$ & $1.68 \pm 0.17$ & $1.79 \pm 0.25$ \\
$C_{\max }(\mathrm{mg} / \mathrm{L})$ & $37.13 \pm 6.01^{\mathrm{b}}$ & $27.14 \pm 4.67$ \\
\hline${ }^{\mathrm{D}} P<0.05$, when compared to R-ORT
\end{tabular}

\section{Plasma protein binding capacity of enantiomers of ORT}

The degrees of plasma protein binding of four different concentrations of S-ORT and R-ORT ranged from 5.12 to $5.59 \%$, and from 5.13 to $5.62 \%$, respectively (Table 2 ). There were no evidence of stereoselective differences between the two enantiomers.
Table 2: Percentage protein binding capacities of ORT enantiomers after $24 \mathrm{~h}$ of dialysis

\begin{tabular}{lcccc}
\hline $\begin{array}{l}\text { Initial } \\
\text { concentration } \\
(\mu \mathrm{gg} / \mathrm{mL})\end{array}$ & $\mathbf{0 . 5}$ & $\mathbf{2}$ & $\mathbf{1 0}$ & $\mathbf{4 0}$ \\
\hline $\mathrm{S}-\mathrm{ORT}$ & $5.12 \pm$ & $5.43 \pm$ & $5.27 \pm$ & $5.59 \pm$ \\
& 0.50 & 0.52 & 0.54 & 0.76 \\
\hline R-ORT & $5.13 \pm$ & $5.43 \pm$ & $5.35 \pm$ & $5.62 \pm$ \\
& 0.51 & 0.72 & 0.65 & 0.57 \\
\hline
\end{tabular}

\section{DISCUSSION}

In the present study, there was no interconversion of S-ORT and R-ORT after oral administration, and the plasma concentrations of $\mathrm{S}-\mathrm{ORT}$ at $1,1.5$ and $2 \mathrm{~h}$ were significantly higher than those of R-ORT. The $C_{\max }$ and $A U C_{0-\infty}$ of SORT were also larger than those of R-ORT. While these results are in agreement with those reported in beagle dogs [8], they are however not consistent with results obtained in some previous studies $[9,10]$. In the present study, there was no significant differences in $\mathrm{Cl}$ values of both enantiomers, but the $C_{\max }$ of S-ORT was significantly higher than that of R-ORT. This result appears to suggest that the differences in the pharmacokinetics of the two enantiomers may be partly due to their different rates of absorption. Results from previous studies on beagle dogs indicated significant differences in the rates of absorption of the two enantiomers after oral administration [11-14]. In the classical theory of pharmacology, the higher the concentration and rate of absorption of a drug, the better its effect. Other parameters of S-ORT were not significantly different from those of $R$ ORT after oral administration. This seems to suggest that there is probably no difference in the metabolism and excretion of both enantiomers. In this study, there were no evidence of stereoselective differences between the two enantiomers, an indication that the differences in their pharmacokinetics may not be related to their plasma protein binding capacities.

\section{CONCLUSION}

There are significant absorption differences between the two enantiomers of ORT. Thus, the enantiomers may differ in their pharmacological effects.

\section{DECLARATIONS}

\section{Acknowledgement}

This work was supported by grants from the Doctoral Scientific Research Foundation of Wannan Medical College (No. 06020241). 


\section{Conflict of interest}

No conflict of interest is associated with this work

\section{Contribution of authors}

This work was done by the authors named in this article and the authors accept all liability resulting from claims which relate to this article and its contents. The study was conceived and designed by Yu-Feng Wen; Wu-San Wang, Yu-Feng Wen collected and analysed the data; Wu-San Wang wrote the text and all authors have read and approved the text prior to publication.

\section{REFERENCES}

1. Edmond S, Zhijiang L, Qin GF, Daniel S, Jay G. Chiral pharmaceuticals: $A$ review on their environmental occurrence and fate processes. Water Res 2017; 124: 527-542.

2. Zdenek H, Ivan K. Oxiracetam pre- but not post-treatment prevented social recognition deficits produced with trimethyltin in rats. Behav Brain Res 2005; 161(2): 213219.

3. Zdeněk $H$, Jarmila $V$, Evžen $K$. Effect of alaptide, its analogues and oxiracetam on memory for an elevated plus-maze in mice. Eur J Pharmacol 1996; 314(1-2): 1 7.

4. Cesare M, Bastian H, Thomas D, Juergen B. Delayed emergence of effects of memory-enhancing drugs: implications for the dynamics of long-term memory. Proc Natl Acad Sci 1994; 91(6): 2041-2045.

5. Cesare $M$, Hans $J M$, Jürgen $B$. The GABAB receptor antagonist CGP 36,742 and the nootropic oxiracetam facilitate the formation of long-term memory. Behav Brain Res 1996; 77(1-2): 223-225.

6. Chiodini LSB, Pepeu GFU. Composition comprising soxiracetame for use as nootropic. WO 1993.
7. Wan L, Huihui L, Hanjie J, Chen W, Yongfei G, Yi S, Xin $Z$, Xin X, Xianhua Z, Ke Z, et al. (S)-Oxiracetam is the active ingredient in oxiracetam that alleviates the cognitive impairment induced by chronic cerebral hypoperfusion in rats. Sci Rep 2017; 7(1): 10052.

8. Russell WM, Burch SR. 1959. The Principles of Humane Experimental Technique. London, UK: Methuen.

9. Wusan W, Hui J, Tingting L, Yuanwei J, Haitang $X$. Pharmacokinetic comparisons of $S$-oxiracetam and $R$ oxiracetam in beagle dogs. Acta Pharm 2016; 66(2): 279-287.

10. Qiuyang Z, Wei Y, Qing Z, Yue Y, Junxiu L, Yang L, Yi Z, Jiake $H, D i Z$, Xijing $C$. Enantioselective HPLC determination of oxiracetam enantiomers and application to a pharmacokinetic study in beagle dogs. $J$ Chromatogr B Analyt Technol Biomed Life Sci 2015; 994: 9-13.

11. Wu-san W, Hui J, Hai-tang Xie, Min D, Yuan-wei J, Da-hu L, Lei Y, Zu-yuan R. A sensitive and specific UPLCMS/MS analysis and preliminary pharmacokinetic characterization of S-oxiracetam in beagle dogs. Chin J Clin Pharmacol Ther 2012; 17(9): 988-994.

12. Lecaillon JB, Dubois JP, Coppens H, Darragon $T$, Theobald W, Reumond G, Beck H. Pharmacokinetics of oxiracetam in elderly patients after $800 \mathrm{mg}$ oral doses, comparison with non-geriatric healthy subjects. Eur $J$ Drug Metab Pharmacokinet 1990; 15(3): 223-230.

13. Perucca E, Albrici A, Gatti G, Spalluto R, Visconti $M$, Crema A. Pharmacokinetics of oxiracetam following intravenous and oral administration in healthy volunteers. Eur J Drug Metab Pharmacokinet 1984; 9(3): 267-274.

14. Perucca E, Parini J, Albrici A, Visconti M, Ferrero E. Oxiracetam pharmacokinetics following single and multiple dose administration in the elderly. Eur J Drug Metab Pharmacokinet 1987; 12(2): 145-148.

15. Qiuyang Z, Wei Y, Yue Y, Han X, Qing Z, Junxiu L, Yang $L$, Jiake $H$, Shuoye $Y, D i Z$, et al. Comparative pharmacokinetic studies of racemic oxiracetam and its pure enantiomers after oral administration in rats by a stereoselective HPLC method. J Pharm Biomed Anal 2015; 111: 153-158. 